\title{
Bottom-Up Strategies for Shared Mobility and Practices in Urban Housing to Improve Sustainable Planning
}

\author{
Jutta Deffner $^{1, *\left(\mathbb{D}, \text { Jan-Marc Joost }^{1}, \text { Manuela Weber }^{2} \text { and Immanuel Stiess }\right.}{ }^{1}$ \\ 1 ISOE-Institute for Social-Ecological Research, 60486 Frankfurt, Germany; joost@isoe.de (J.-M.J.); \\ stiess@isoe.de (I.S.) \\ 2 Oeko-Institut e.V., 13189 Berlin, Germany; m.weber@oeko.de \\ * Correspondence: deffner@isoe.de
}

check for updates

Citation: Deffner, J.; Joost, J.-M.; Weber, M.; Stiess, I. Bottom-Up Strategies for Shared Mobility and Practices in Urban Housing to Improve Sustainable Planning. Sustainability 2021, 13, 2897. https://doi.org/10.3390/su13052897

Academic Editor: Marilisa Botte

Received: 15 December 2020

Accepted: 2 March 2021

Published: 8 March 2021

Publisher's Note: MDPI stays neutral with regard to jurisdictional claims in published maps and institutional affiliations.

Copyright: (C) 2021 by the authors Licensee MDPI, Basel, Switzerland. This article is an open access article distributed under the terms and conditions of the Creative Commons Attribution (CC BY) license (https:/ / creativecommons.org/licenses/by/ $4.0 /)$.

\begin{abstract}
Recent years have seen the development of numerous innovations in social, constructional, and transportation planning for different forms of communal housing. They illustrate how more sustainable practices in transport and land use can be achieved through the collective provision and use of space and mobility services. The question remains, however, of who needs to be involved in such bottom-up approaches and when in order to ensure their success. What changes are necessary to anchor these approaches in the wider context of urban and transport planning? This paper presents three examples of neighbourhood mobility concepts and the collaborative use of space and land. A research project accompanied the development of these concepts in a real-world laboratory design. The scientists used social-empirical methods and secondary analyses to evaluate social and ecological effects, economic viability and the process of joint development. The results show the high sustainability potential of such neighbourhood concepts: they enable residents to meet their mobility needs, while using fewer vehicles through shared use, reducing the number of journeys and changing their choice of transport. At the same time, promoting and developing community services has been shown to be inhibited by preconditions such as existing planning law. Opportunities and obstacles have been identified and translated into recommendations for action, focusing on municipal urban planning, transport planning, and the housing industry.
\end{abstract}

Keywords: sustainable urban mobility; shared mobility; land use and accessibility; co-housing; integrated urban and transport planning; bottom-up planning; real-world laboratory

\section{Background and Motivation}

Different forms of co-housing have been emerging from bottom-up approaches for several years [1]. The estimated number of co-housing initiatives in Germany has now grown to over 3000 [2], and while their number is still relatively small, their impact as role models for a more sustainable way of living is of great importance. Bottom-up planning in the housing industry could have the potential to transform the nexus between the housing and transport sectors and therefore the entire urban structure. Shared mobility is skyrocketing in cities worldwide. Most sharing services such as car sharing and the sharing of micromobility (e.g., bicycles, electric scooters) are of commercial character and form a subset of a larger sharing economy [3]. Nonetheless, non-commercial and communal forms of sharing are of crucial importance for enhancing urban sustainability as well [4] and form the research object of this paper. Research on co-housing-based sharing services has been conducted since the early 2000s and services have been systematized and studied in terms of their sustainability potential $[5,6]$. Numerous studies point to the positive sustainability impacts of these services: from an ecological, social, and economic perspective as they can reduce the number of trips, change the use of transport modes, and facilitate equal access opportunities for residents [7-10]. Communal forms of sharing are also particularly relevant in the context of the global COVID-19 pandemic. While pandemic prevention measures impose strict limitations on individual mobility [11,12], findings indicate that these 
restrictions affect low-income households particularly acutely [13]. Communal sharing can be of key importance here [14]: it offers an alternative to commercial services enabling more crisis-resilient forms of mobility through building on existing networks of trust.

The sustainability potential of co-housing initiatives has been proven by a multitude of studies. In a systematic review of quantitative studies on community-based initiatives (also known as intentional communities), Daly [7] compared studies on 23 different cohousing and ecovillage projects, located mostly in Europe and North America. He found that community-based initiatives have a much lower environmental footprint than regional conventional settlements: on average, the ecological footprint was $50 \%$ and the carbon footprint around $35 \%$ lower. Additional evidence from the vast majority of studies strongly indicates that these community-based initiatives do indeed achieve lower environmental impacts than comparable mainstream communities. The studies agree that two of the most significant factors contributing to the lower ecological footprint of community-based initiatives were housing and transportation. Regarding co-housing, the sharing of communal spaces and shared mobility are the main drivers of a reduced ecological footprint $[15,16]$. Behavioural patterns also play an important role and are considered by some studies to be more important for ecological sustainability than physical infrastructure [17,18].

Steps to more sustainable urban living concepts have recently been taken by a variety of community-based initiatives. These initiatives can take on different organisational forms such as building societies and associations, or they can be part of housing companies and co-operatives with a common interest. These initiatives can result from either bottom-up or top-down approaches. Studies comparing top-down and bottom-up approaches in co-housing have shown substantial differences. Top-down interventions aim primarily on technical solutions and individual behavioural change and have had little impact on residents' mobility and energy consumption patterns. In contrast, bottom-up approaches were much more successful in reconfiguring the daily behaviour of residents to become more sustainable [9]. This difference is due to the specific philosophy and governance structure in community-based initiatives opening up a greater scope for experimenting with novel practices. Distinctive features of community-based initiatives such as co-housing are that members have a shared vision, shared values, and collective decision-making processes. These communities are thus able to define strong collective agreements, standards, or even binding rules in order to reconfigure daily practices towards more sustainable practices. Moreover, measures can be taken in multiple areas (mobility, housing, energy, etc.) and be combined into integrative approaches. This allows for more integral modification of behaviour instead of top-down interventions targeting only single behaviours. By altering housing and mobility routines via a bottom-up approach, co-housing initiatives reconfigure daily practices, develop social innovations, and act as laboratories for social and structural change. Hence, they offer experiences and inspiration for societal transformation on a broader scale [9]. In contrast to this, traditional top-down planning strategies tend to neglect the need to create structures enabling residents to adopt more sustainable behavioural patterns. While top-down planning is appropriate on regional and more strategical levels, bottom-up approaches are described as most suitable on local scales, as pointed out by Pissourios [19]. By embedding planning processes at a neighbourhood level in the context of social relations and the day-to-day practices of its residents, decisions are based on consensus-building practices. They are highly adaptable to local circumstances $[19,20]$ and foster a so-called "participative urbanism" [21].

The core characteristic of a bottom-up approach is therefore the joint decision-making process. The involvement of all residents supports sustainable planning principles that enable short distances between areas such as living, working, leisure, and care work [22]. Diverse forms of co-housing typically combine a broad range of goals such as providing affordable housing for several generations, socio-cultural diversity and the exchange of ideas and experiences between the residents, the promotion of environmentally friendly mobility, the design and creation of an atmosphere of harmony in building and living, and the realisation of high energy and resource efficiency. In order to realise one or 
more of these objectives, many initiatives offer residential services. These can include jointly organised car sharing services, food co-ops, joint workshops, community gardens, open spaces, or common rooms, depending on the interests and needs of the residents. Schneidewind and Scheck [23] state that such services, if disseminated, can function as system innovations and initiate change processes by establishing new practices in sociotechnical systems. However, there are hardly any approaches or case studies to find out how such services emerge and how they work [24]. Moreover, it is often stated by residents in co-housing initiatives that social innovations require a high level of commitment and considerable personal effort, which is difficult to sustain on a voluntary basis in the long run without incurring extra cost. Nonetheless, many municipal housing companies and traditional co-operatives would like to support and renew the idea of community and common good and therefore add some elements to their main business models where they include co-housing.

Many of these approaches have now also been taken up by the commercial housing industry and are marketed under keywords such as serviced housing or micro apartments. Although these housing concepts also offer shared services, this is more likely to come from top-down planning rather than through a joint negotiation and development process. In other words, they offer only isolated elements of integrated co-housing services and are not aiming to strengthen sustainability. Time-intensive bottom-up processes that allow for user participation and reciprocal relationships are mostly ruled out by commercial housing providers for being unprofitable. From their perspective, bottom-up community services are still not particularly marketable nor economically viable. However, it is through those bottom-up processes that progressive planning principles are often implemented [9].

Up-to-date, bottom-up approaches are usually the result of individual efforts and are often out of line with existing planning policies and regulations (such as parking space requirements). This makes implementation challenging and hinders the diffusion of bottom-up practices. Scaling up, in the sense of introducing similar projects to other parts of the housing sector, has proved difficult.

In this paper, we explore the overall research question of how co-housing initiatives can contribute to foster more sustainable mobility and space-use practices. From this overall objective, the following research questions and corresponding hypothesis are deduced: a first research question is how the sustainability of co-housing-related services can be assessed appropriately (Q1). Our hypothesis is that sustainability potentials of participatorily created co-housing initiatives can only be fully understood if their ecological, economic, and social impacts are taken into consideration, applying an integrated evaluation framework (hypothesis H1). The second research question is how transport and urban planning processes can be designed in order to enable and promote sustainable co-housing approaches (Q2). Our hypothesis is that the sustainability impact increases with an early integration of the service design in the overall planning process $(\mathrm{H} 2)$. In addition, we focus on how actors can be actively involved in each stage of the planning and implementation process (Q3). We assume that contextual factors play an important role, because of strong interrelationships between framework conditions and participating actors. We suppose that the active involvement of all stakeholders potentially involved strengthens the potential of bottom-up approaches to reconfigure the daily practices of residents to become more sustainable. By enhancing this participative element, co-housing can better adapt their residential services to users' needs (H3). The relationship between user and institutional actors, especially housing providers, is one of the lesser studied aspects of co-housing [1].

To answer these questions, this paper builds on the empirical results of the transdisciplinary research project "WohnMobil", conducted from 2016 to 2018 [24-27]. The aim of this research project was to investigate how residential sharing services linking sustainable housing- and mobility-related practices can be fostered and scaled up to contribute significantly to a social-ecological transformation. It investigated three co-housing initiatives in Germany which implemented different forms of shared services. 
Drawing on the results and experiences gained in the research project, opportunities and obstacles can be identified and translated into recommendations for community housing groups, housing providers, municipal planners, and bodies at state or federal level. Furthermore, the role of the different actors (community members, internal and external experts, and key players) will be analysed. This paper is structured as follows: Section 2 presents the research framework, the case studies and the theoretical and methodical approach of the "WohnMobil" project. The results relevant to the research question of this paper are presented in Section 3. In Section 4, there follows a discussion that compares the findings and points out similarities and differences. These are then translated into recommendations for action in Section 5.

\section{Research Frame (Real-World Laboratories) and Methods}

The empirical investigation is based on a research framework, applying a real-worldlaboratory (RWL) approach. In a first step, the underlying RWL research concept is described. Subsequently, the design of the research is outlined briefly before going on to describe the method of analysis for the sustainability impact assessment.

\subsection{Research Framework}

In order to explore how housing-related services evolve from bottom-up and how and by whom these processes can be supported, a RWL approach was chosen as an appropriate research framework. The RWL approach provides a feasible framework for triggering and studying sustainability transformations which is open enough to be developed further together with stakeholders and practitioners enrolled in the research process [28]. A RWL is a research concept that produces transdisciplinary knowledge for sustainability transformations in real-world settings [29,30], for instance by developing solutions to local sustainability problems [31] and studying them under controlled conditions. It therefore refers to "a social context in which researchers conduct interventions ( ... ) to learn about social dynamics and processes ( ... ) There are close links to concepts of field and action research" [32]. An RWL approach is particularly suited to exploring the conditions under which socio-technical innovations evolve in a joint process of science and practice and can be transferred to other contexts. On the one hand, knowledge transfer processes are initiated, and on the other hand, these processes are accompanied and examined with regard to their potential and effects (see Section 2.3). The RWL concept manifests a threefold approach towards research and societal problems: they are normative in character and seek to bring about long-term transformation, they deploy transdisciplinary methods, and they operate under lab-like conditions. Their main outcome is the provision of orientation knowledge to help understand the possibilities and boundaries of potential decisions, and of transformation knowledge fostering sustainable changes [33].

The research structure of the RWL was combined with a sustainability assessment approach (see Section 2.3). Sustainability assessments usually refer to very specific contexts that need to be taken into account and are concretely addressed accordingly when choosing individual sustainability indicators. Assessment concepts on a small-scale (e.g., neighbourhoods) also invoke sustainable development goals (SDGs), such as those outlined by Reyes Nieto et al. [34]. Holistic consideration of ecological, institutional, and economic aspects are the main parameters. In a review on recent urban sustainability assessments, Reyes Nieto et al. [34] concluded that social indicators are considered only to a lesser extent in the analysed literature. They developed their own holistic approach that considers social indicators to be of a higher weight in the analysis. The assessment approach developed and applied in this study addresses these points accordingly (see Sections 2.3.1-2.3.3). Figure 1 shows the schematized research framework. 


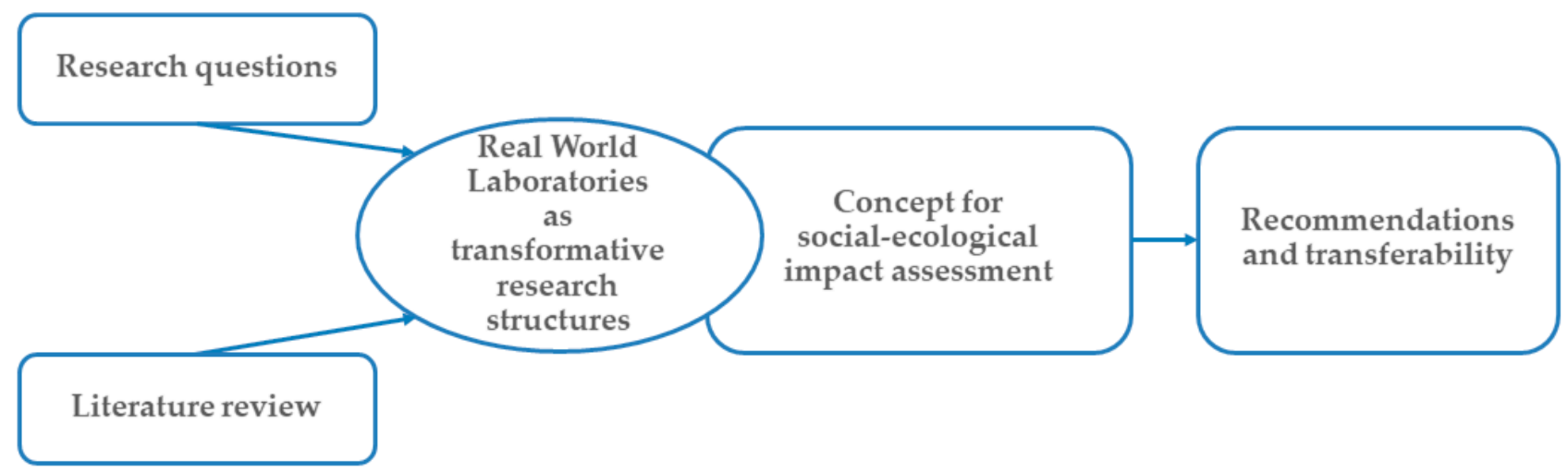

Figure 1. Research framework.

The RWL approach offers a flexible and adaptive research framework to generate transdisciplinary knowledge on enablers and inhibitors of sustainability transformation processes, fostering social learning among researchers and stakeholders. In many cases, the RWL approach is used in an explorative way. In our study, the RWL approach is combined with sustainability assessment methods (see Section 2.2). This methodology is applied for a structured and cross-cutting investigation of three RWL processes, drawing on the research questions and hypotheses which were developed in the previous chapter.

\subsection{Development of Shared Residential Services in Real-World Laboratories}

The project focused on new forms of co-operation among residents, and between residents, housing suppliers, and service providers. A major task was therefore to develop and integrate various types of knowledge (on residents' needs, scientific and expert input on sustainability services, and economic constraints).

Embedded in the RWL design, three co-housing initiatives were selected for the WohnMobil project. During a one-and-a-half-year process, the research team supported the development of residential sharing services, which were subsequently evaluated for their sustainability impacts. The specific services were planned and implemented together with the residents of a housing association complex in the city of Pirmasens (34 housing units, approximately 50 residents) and two co-housing initiatives, one located in Berlin and one in its surrounding area (henceforth referred to as Greater Berlin), each having approximately 70 housing units and 120-150 residents. The residents of the co-housing initiative in Pirmasens moved in between 2015 and 2017, while those of the initiative in Greater Berlin took up residence during the period 2016-2017. In contrast, the residents of the co-housing initiative in Berlin had already been living there since 2014, prior to the start of the RWL.

All initiatives offered various shared services adapted to the respective residents, but for each RWL one service was selected as the focal point of implementation and analysis. In the case of the Pirmasens co-housing initiative, this was the creation of a multifunctional common room, equipped by the participants as a fitness room with an area for handicrafts/DIY (see Figure 2, left). Concepts for neighbourhood mobility services were installed at the co-housing initiatives in Greater Berlin and Berlin itself. These included institutionalised, flexible, and unbureaucratic neighbourhood car sharing via a booking and billing platform that integrated usage fees, jointly regulated insurance, and jointly agreed terms of use (see Figure 2, right). The service also extended to bicycles and cargo bikes, handled via informal sharing. 

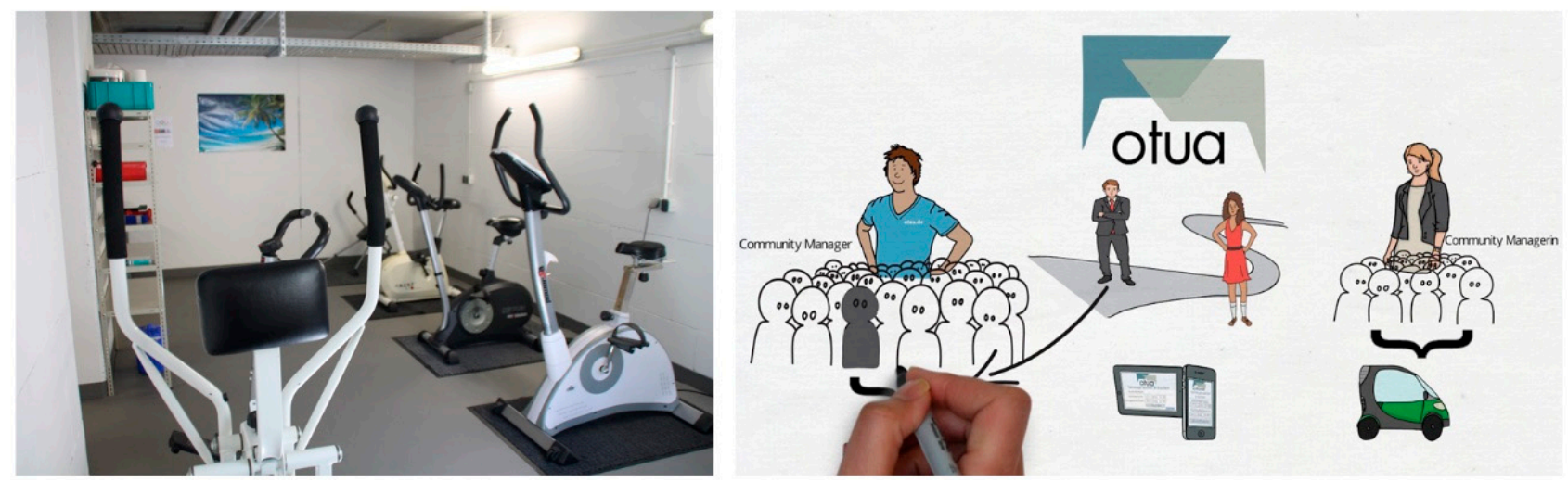

Figure 2. Examples of the multifunctional room (used as a fitness room) and the mobility-sharing tool used for the neighbourhood sharing services (Source: WohnMobil project, otua.de).

The set of co-housing initiatives selected covers a range of different conditions in terms of organisational and legal structures and the composition of tenants. Furthermore, the different settings included urban and sub-urban locations and very different preconditions regarding mobility patterns and car ownership. For more detailed information about the three co-housing initiatives, see Table 1.

Table 1. Overview of the co-housing initiatives investigated.

\begin{tabular}{|c|c|c|c|}
\hline Co-Housing Initiative & Co-Housing Pirmasens & Co-Housing Greater Berlin & Co-housing Berlin \\
\hline Households (residents) & $34(\sim 50)$ & $55(\sim 160)$ & $65(\sim 190)$ \\
\hline Spatial setting & $\begin{array}{l}\text { New buildings in urban } \\
\text { residential area (housing from } \\
\text { the } 1950 \text { s to 1970s) Small } \\
\text { city (shrinking) }\end{array}$ & $\begin{array}{l}\text { Renovated and new buildings } \\
\text { on former industrial siteSmall } \\
\text { city, Berlin metropolitan } \\
\text { area (growing) }\end{array}$ & $\begin{array}{c}\text { New buildings in high-density } \\
\text { urban structure } \\
\text { (Wilhelminic belt of the } \\
\text { 1990s)Berlin (growing) }\end{array}$ \\
\hline $\begin{array}{l}\text { Socio-demographic } \\
\text { characteristics }\end{array}$ & Older residents (aged 60+) & $\begin{array}{l}\text { Mix of young families, } \\
\text { couples, older people }\end{array}$ & Young families and couples \\
\hline Legal form & Housing companies/tenants & Co-operative & Owner association \\
\hline Shared residential services & $\begin{array}{l}\text { Multi-functional room *, } \\
\text { community garden, } \\
\text { neighbourhood café }\end{array}$ & $\begin{array}{l}\text { Mobility services * } \\
\text { (neighbourhood-based car } \\
\text { sharing, cargo bike sharing, } \\
\text { public transport ticket } \\
\text { sharing), food co-op, } \\
\text { workshop room, } \\
\text { common room }\end{array}$ & $\begin{array}{l}\text { Mobility services * (informal } \\
\text { neighbourhood based car } \\
\text { sharing, cargo bike sharing, } \\
\text { sharing of recreational } \\
\text { vehicles), open workshops, } \\
\text { sauna, co-working spaces, } \\
\text { common room, } \\
\text { community garden }\end{array}$ \\
\hline Practice partners & $\begin{array}{l}\text { Housing association (manager, } \\
\text { social manager), residents }\end{array}$ & $\begin{array}{c}\text { Community delegates } \\
\text { (working group), residents }\end{array}$ & $\begin{array}{c}\text { Community delegates } \\
\text { (working group), residents }\end{array}$ \\
\hline $\begin{array}{l}\text { Form of community } \\
\text { participation and delegation }\end{array}$ & $\begin{array}{l}\text { Sub-group of residents } \\
\quad(7-12 \text { members })\end{array}$ & Working group (5-7 members) & Working group (2-5 members) \\
\hline $\begin{array}{l}\text { Empirical and participatory } \\
\text { methods }\end{array}$ & $\begin{array}{l}\text { Standardised survey } \\
\text { (telephone), group } \\
\text { discussions, workshops with } \\
\text { community group meetings } \\
\text { (5 meetings) }\end{array}$ & $\begin{array}{l}\text { Standardised longitudinal } \\
\text { survey (online), workshops } \\
\text { with working group and } \\
\text { resident group ( } 3 \text { meetings) }\end{array}$ & $\begin{array}{l}\text { Standardised longitudinal } \\
\text { survey (online), workshops } \\
\text { with working group } \\
\text { ( } 2 \text { meetings })\end{array}$ \\
\hline
\end{tabular}




\subsection{Sustainablity Impact Assessment}

The researchers analysed and evaluated the use of the services and their effects over several months during the establishment, use, and further development of the shared residential services. Figure 3 shows an abstract model of the process of the RWL.

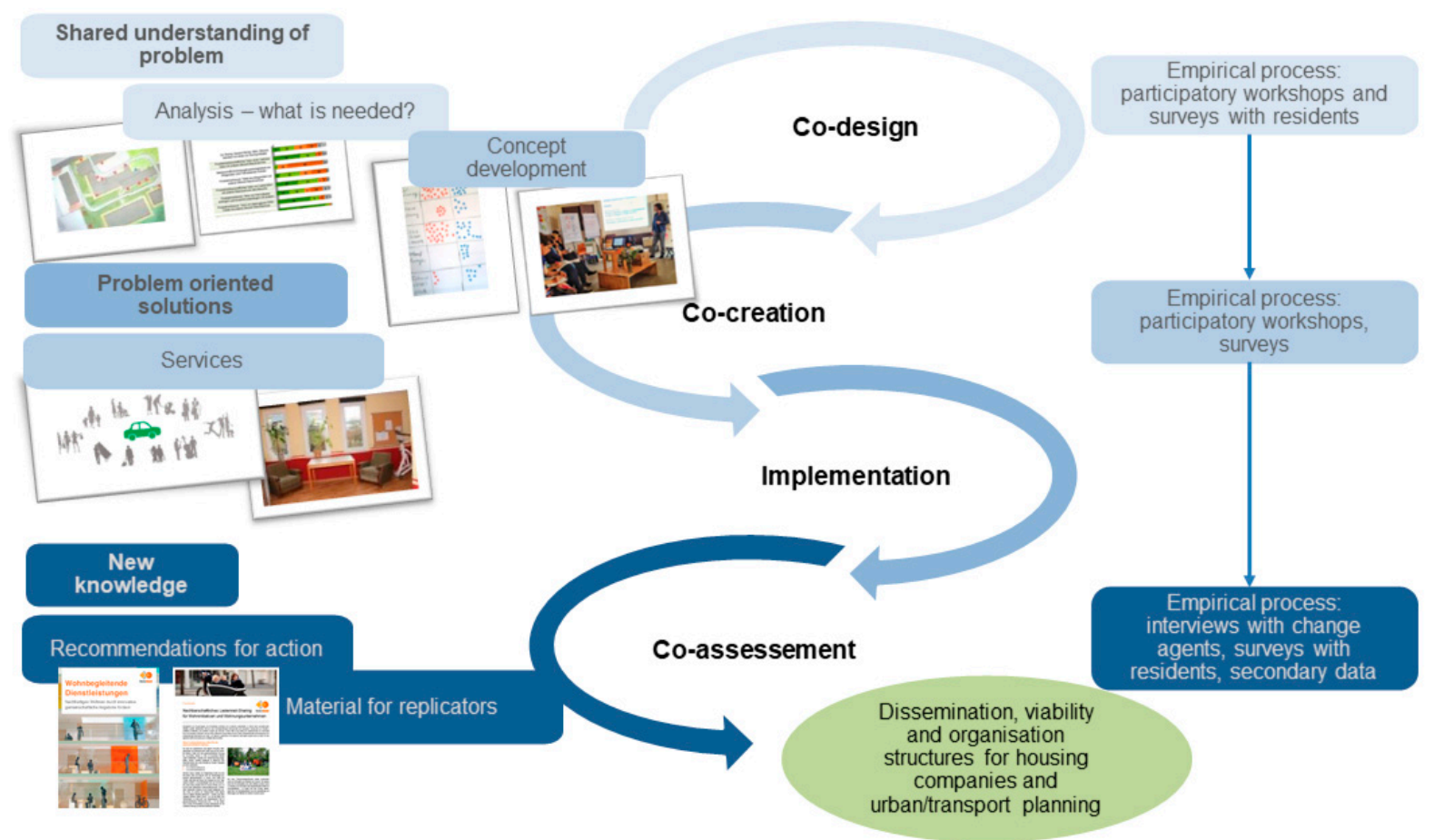

Figure 3. Idealised process for the real-world laboratories in the WohnMobil project.

\subsubsection{Review of Sustainability Indicators}

The review and inclusion of existing sustainability indices (SDG, German Sustainability Strategy, OECD Better-Life Index) initially served as a theoretical basis for the criteria to be considered in the assessment. Inductive derivation from the everyday life of the residents and practice partners was necessary to take account of the respective RWL-specific differences in terms of the spatial setting, various processes, and actors. Findings in this regard were validated through focus group discussions with the residents and community delegates. The sustainability indicators developed in this combined approach could then be validated via empirical surveys and-if necessary-put into an overall context. The evaluation framework that was subsequently developed included social, ecological, and economic impact criteria for the selected services in the three RWLs. The dimensions and indicators for the evaluation are depicted in Table 2.

Table 2. Criteria of the evaluation framework. The elaboration of each criterion differs according to the specific RWL/service.

\begin{tabular}{|c|c|c|}
\hline Ecological & Social & Economic \\
\hline $\begin{array}{ll}- & \text { Land use/cover } \\
\text { - } & \text { Traffic/energy expenditure } \\
\text { - } & \text { Indirect effects: carbon dioxide } \\
& \left(\mathrm{CO}_{2}\right) \text { emissions } \\
\text { - } & \text { Number of vehicles owned } \\
\text { - } & \text { per household } \\
& \text { Resource expenditure }\end{array}$ & $\begin{array}{ll}\text { - } & \text { Social interaction } \\
\text { - } & \text { Social justice/equal opportunities in } \\
\text { - } & \text { access to services } \\
\text { - } & \text { Quabling time sovereignty } \\
& \text { Quality of stay }\end{array}$ & 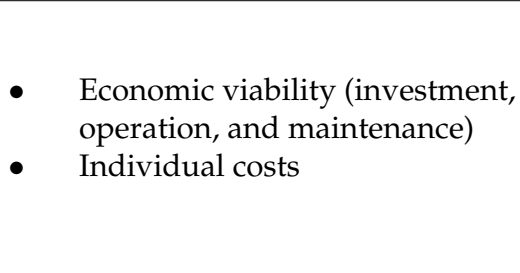 \\
\hline
\end{tabular}




\subsubsection{Empirical Methods for the Impact Assessment}

The specific situations in the three RWLs required a combination of qualitative and standardised social research methods to ask the residents about the services and assess the evaluation indicators. Focus groups and surveys via the internet or telephone were used as a primary source of information (see Figure 3). In addition, further quantitative data on the structure and use of the services was collected and supplied directly by the contact persons in the RWL and through the analysis of secondary data [26]. The process evaluation was achieved by methods such as interviews with the delegates and focus group discussions. Not all survey methods were applied equally in all RWLs. In the initial phase of the RWL, it became evident that some of the residents (especially in the Pirmasens co-housing initiative) were more easily activated and creative when the survey formats were integrated into regular meetings and resident interactions, since the focus here was more on the routines of the more elderly residents. For this reason, the survey methods were adapted gradually. In the initial phase, a focus group and a survey via the internet or telephone were chosen to find out about the residents' interests and the potential use of various services. However, the low response to the telephone survey indicated that for later surveys face-to-face interviews would enjoy greater acceptance among the residents. This was taken into account in the surveys towards the end of the RWL phase.

The different empirical steps were integrated into a comprehensive analysis for evaluation. The qualitative results were categorised according to the evaluation criteria and supplemented with quantitative evaluations. Quantitative data, such as frequency of use, were particularly relevant for the economic evaluation. Where both standardised and qualitative data were available, the qualitative results were categorised/content-analysed according to the evaluation criteria and supplemented with quantitative evaluations. At the same time, the results of the qualitative surveys were included to extend the findings, show differentiations, and explain the background of the distributions.

With regard to the validity and transferability of the standardised survey findings, it is important to point out that they are the results of individual case studies. Although the aim was to conduct comprehensive and representative surveys in all case studies, all three communities consist of a relatively small number of residents (34-65 households), who in turn did not all participate in the surveys (response rate of approximately $60 \%$ ).

The empirical data generated in the WohnMobil project provides the only data source of this paper. No further (social) empirical data were used in this paper.

\subsubsection{Content Analysis and Scaled Assessment}

The survey and evaluation of the empirical steps was followed by an assessment of the sustainability impacts. For this purpose, an analysis concept was developed to relate the empirical results to the previously developed sustainability indicators and criteria. First of all, the qualitative and quantitative statements from the empirical data were interpreted, structured, and assigned to the respective sustainability criteria. The next step was to derive statements on development trends, i.e., the extent to which services can trigger sustainability effects from an ecological, social, and economic perspective. Only after the results had been assigned to the evaluation categories could evaluative statements on the ecological, social, and economic sustainability impacts of the services be made. The impact assessment thus began by taking up these statements and conclusions and condensing them for each sustainability criterion-separated according to RWL and service-before assigning them a rating for their sustainability impact. To support this, the following five-tier scale was used to assess the sustainability impact of residential services.

Based on the evaluation framework (Table 2), it was possible to link the results from our empirical study to the sustainability indicators. The next step was to assess the extent to which the services exert sustainability effects in ecological, social, and economic terms. Using the categorisation scheme (Table 3), each indicator could then be assessed separately. Subsequently, the results per service were aggregated at the level of the sustainability dimensions. The score for each sustainability dimension was derived from the average 
value of its indicators. This procedure enabled an overall evaluation for each service developed in the co-creation process compounded of the three sustainability dimensions. The composition of the detailed evaluation scores for each sustainability indicator allowed a deeper examination of the services established by the three RWLs.

Table 3. Categorisation scheme to assess the sustainability impact.

\begin{tabular}{cc}
\hline Impact Rating & Explanation \\
\hline-- & Substantial deterioration/unlimited negative development \\
- & Slight deterioration/limited negative development \\
0 & No change \\
+ & Slight improvement/limited positive development \\
++ & Substantial improvement/unlimited positive development \\
\hline
\end{tabular}

\section{Results of the Social-Ecological Impact Assessment of Shared Services}

Building on the development of the evaluation categories and the subsequent methods used to evaluate the sustainability impact (see Section 2.3), Section 3 now lists the central results for each of the residential services analysed. Frequency of use and the process of implementing the respective service (see Figure 3) were evaluated in addition to the ecological, social, and economic sustainability effects. The results are summarised in a figure for each service (Figures 4-6).

\subsection{Multifunctional Room at Co-Housing in Pirmasens}

In the basement of one of the buildings, the housing association provided a $37 \mathrm{~m}^{2}$ room for common use. During the construction phase, its interior design and use was planned in co-creation workshops with about 7-12 interested residents (see Table 1). Here, the room was made virtually experienceable and accessible by marking the layout on the floor with adhesive strips (the "user journey" method). The involved residents planned three different uses: an area for collaborative textile work and sewing, a workshop (e.g., handiwork), and a cosy area for meeting and drinking coffee. These interests were further elaborated over a longer period of time and supported by investments from the construction support agency (installation of an emergency exit and a toilet in the basement). In the course of the participatory development process, however, objections to these uses emerged: a lack of interest in the initially planned uses was attributed to the group dynamics as new tenants moved into the newly constructed building. It was then agreed to adapt the uses in order to more adequately accommodate the needs of the residents: the room was ultimately defined as a fitness and multi-purpose room and kitted out by the residents with fitness equipment, a handicraft corner, a couch as a place to meet, and a book exchange. These various uses were implemented in the Spring of 2018. It is planned to adapt the utilisation concept from time to time to meet the needs of the residents.

Currently, the multi-functional room can be used both individually and in groups. Most tenants use it as a fitness room two to three times a week; other uses do not take place regularly. In general, the intensity of use is considered very good.

The assessment of ecological impacts is also positive. Traffic avoidance linked to the use of the multifunctional room can be seen as a significant improvement. All the users who were previously members of a local fitness studio (8 out of 12 users) have cancelled their contract since the fitness room was installed. Hence journeys are avoided that were previously made by car. Based on the previous travel patterns of the tenants, emission savings amount to almost $87 \mathrm{~kg} \mathrm{CO}_{2}$ per year. Most of the fitness equipment was already owned privately and brought in for collective use by the residents. This is seen as positive in terms of reducing resource consumption. Possible savings in residential area requirement could not be evaluated. 
- Positive impulses

- Strengthening of resident participation

- Involvement through workshops
Process: +

- Understanding increased over time

- Multilevel learning processes

- Novel and well accepted utilisation concept
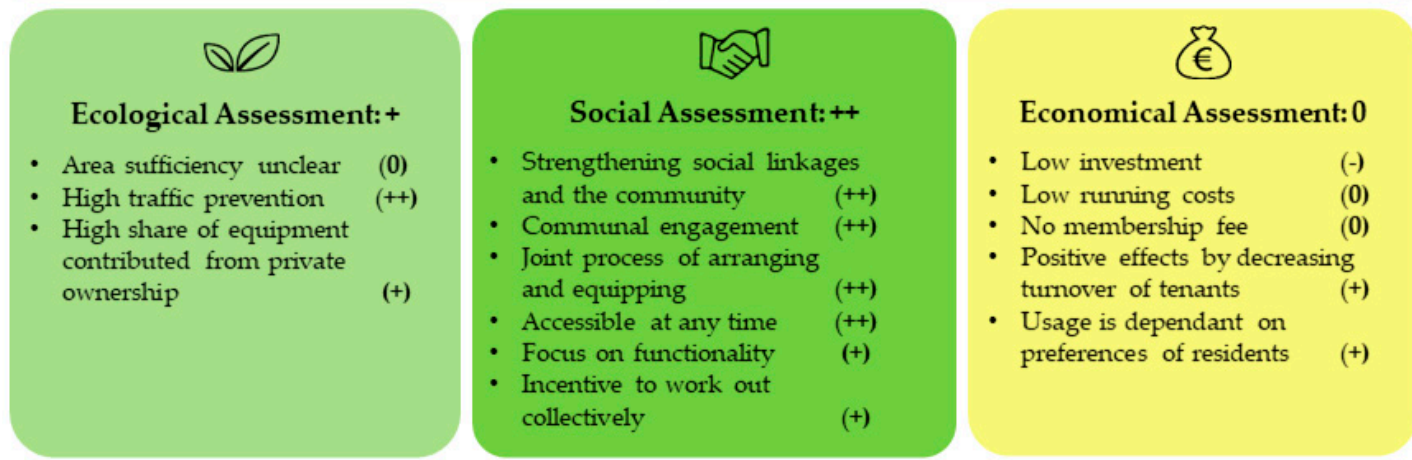

Figure 4. Assessment of the multi-functional room at co-housing in Pirmasens.

- Impulses initated by WohnMobil

- Intensive participation of residents

- Process took several years due to successive move-ins

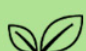

Ecological Assessment: +

- Reducing the parking space requirement

- Intensive use of sustainable means of transport

- Complementing individual practices of traffic avoidance

- Number of private vehicles stagnates (potential decrease)

\section{Process: +}

- Multilevellearning processes

- Demand oriented utilisation concept with a tendency towards formalisation

\section{$(€)$}

Low investment

$(-)$

Positive effects by decreasing

mover of tenants

Usage is dependant on

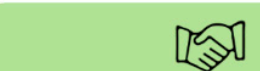

Social Assessment: +

- Online tool is seen as ambivalent

- Strengthening social linkages and the community

- Very high accesibility

- Functionality adapted to mobility needs

- Parking space replaced by communal space

$(++)$

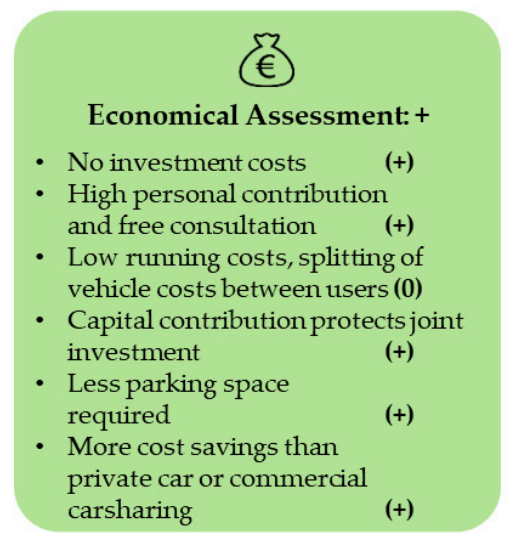

Figure 5. Assessment of the communal mobility sharing at co-housing in Greater Berlin.

- Low impulses

- Difficult participation of residents

- Lengthy process

\section{Process: +}

- Multilevel learning processes

- Demand oriented utilisation concept individually adapted to residents needs

\section{QQ}

Ecological Assessment: 0

- No abolishment of private vehicles

(0)

- Diverse mobility options hinder more intensive use of service

- Sharing used in addition to own vehicles

\section{[29:}

Social Assessment: +

- Strenghtening of the community $(+)$

- Equal access opportunities are intended

- Possibility of different organisational forms

- Advantage of informal sharing: spontaneity \& flexibility

- No influence on layout of outside area

\section{$(€)$}

Economical Assessment: 0

- No additional investment costs

- No maintenance costs

- No implication on value

- Mostly free usage of vehicles and public transportation tickets

- Neigbourly help instead of refinancing

Figure 6. Assessment of the informal mobility sharing at co-housing in Berlin. 
From the very beginning, developing the multi-functional room at the co-housing initiative in Pirmasens was grounded in the housing association's strong commitment to solidarity principles. Once the utilisation concept for the room had been clarified, the social effects became obvious and were evaluated very positively. The decision to make fitness the primary use was taken by the tenants unanimously. Shared use of this facility strengthens both social cohesion and the will to maintain personal health. The room is quick to reach and open to every resident at any time without access restrictions. It also brings financial relief because there are no costs apart from the low operating costs, which are split among all residential units.

The economic evaluation of the multifunctional room showed neutral effects. As it became clear early on that no direct revenues could be generated, care was taken to limit investments as far as possible. A room with relatively low provision and opportunity costs was selected. Costs of just over $€ 12,000$ were incurred for the first-time provision of the room. The major part of these costs related to the installation of an emergency exit, sanitary facilities, and the necessary electrical fittings. Thanks to the users' own contributions, the annual costs for management and maintenance are below $€ 1000$. By improving the attractiveness of the premises, with possible positive effects on tenant fluctuation, positive value implications for the buildings can likely be achieved to a small extent. However, the individual cost-benefit analysis and the actual use of the multi-functional room always depend on the structure of the residents and potential users.

The process of developing the multifunctional room shows that an iterative approach can have positive effects on the quality of service. The following process characteristics were considered most important in this respect: (1) a very targeted, group-specific participation concept involving the dedication of single residents, which ensured residents remained interested and committed despite the lengthy process; and (2) the impulses provided by the local construction support agency (regarding a pragmatic solution to respect the building law) and the research project team (see also Section 5).

\subsection{Mobility Sharing at Co-Housing in Greater Berlin}

The first forms of neighbourhood-based car sharing were already being practiced at the co-housing initiative in Greater Berlin when the initiative started in 2015. Back then, this mainly consisted of informally borrowing a car from a neighbour or community member. In the course of the co-creation process and fuelled by growth through continuous move-ins, the demand for an institutionalised sharing of cars became apparent for most community members. Car sharing had to become easier, regulated, and more flexible for borrowers, and at the same time offer more security in terms of planning and damage regulation. The co-creation process included workshops where external experts presented different organisational models for sharing (e.g., informal sharing using information and assistance tools, the founding of a car sharing association); these concepts were then discussed with the residents. As a result, specific organisational and financial models for use were identified and adjusted to the specific needs of the initiative.

In the next step, the lending via bilateral agreements was transformed into organised lending via the intranet and e-mail distribution lists. Finally, a co-creation workshop provided the basis for the decision to mainly use an online booking platform to organise neighbourhood car sharing in the future. The digital planning and booking platform of choice was "otua". This platform was initially developed by a residential initiative in Hamburg. In close co-operation with the project team, the platform was adapted to the specific needs of residents at the co-housing initiative in Greater Berlin (e.g., booking on an hourly basis, inclusion of other modes of transportation in the booking system). In addition, a small set of lending and usage rules were established to regulate the jointly organised sharing. Since then, the sharing of mobility between neighbours has been organised both informally and formally. The sharing platform was completed by structural measures such as publicly accessible key boxes. The mode of organisation ultimately chosen by the residents (directly from the neighbour, via intranet, or via the online booking tool) 
depends strongly on the means of transport to be borrowed, purpose, frequency of use, and individual preference regarding social interaction. For cars, booking via "otua" is predominantly preferred, whereas public transport tickets and cargo bicycles tend to be shared on an uncomplicated, spontaneous, face-to-face basis.

Although the frequency of renting the different means of transport differs, it can still be described as very high overall. The highest demand is for cargo bikes and public transport tickets. These are borrowed several times a week, with peaks outside normal working hours, preferably on weekends and in the evening. Car rentals are less frequent. This low rate of use also reflects the self-conception of the residents: their strong desire to avoid car ownership and car use is first and foremost a reflection of the ecological orientation of the residents.

A key motivation for the implementation of mobility sharing was to reduce the amount of parking space on the property. This succeeded: instead of the 71 car parking spaces that were officially designated, the co-housing initiative in fact requires only 31 parking spaces. The small number of cars is also due to the prevailing lifestyles of the group. Despite the suburban location, half the households surveyed live without a car. Furthermore, $40 \%$ of car owners plan to abolish their car in the future without replacement. This points to positive effects in terms of ecological sustainability.

While social interactions are very important for the residents of the initiative, the effect of the mobility concept on social interaction is of secondary importance. The use of the digital booking and billing platform "otua" is appreciated and supported by some residents for reasons of practicability and effectiveness, whereas others fear it will reduce direct social interaction. Therefore, they deliberately choose not to use this service. However, the residents are free in their choice of lending options. Positive effects on social sustainability are due to the intensive efforts to provide all residents with the best possible access to mobility and the high functionality of the services adapted to the specific mobility needs of the residents.

The initiative was able to offer jointly organised mobility sharing for its residents with only minor financial expenditure of its own (membership fee for re-investments). All vehicles and public transport tickets used were already privately owned and are now used more intensively thanks to the sharing between neighbours. However, the lack of financial expenditure is offset by a considerable personal contribution. In the meetings of the mobility working group to promote the development of the joint concept, the members together have invested around $100 \mathrm{~h}$ of their own labour. The knowledge of external experts was also brought in as part of the co-creation process. The costs of approximately $€ 3200$ were covered by the project budget and did not have to be provided by the initiative. The running costs for the operation of neighbourhood mobility services are minimal thanks to the voluntary work. For the organisational tool, internal communication and other operations, only management fees incur, which amount to around $€ 50$ a year. Organisation and accounting work amounts to a maximum of $10 \mathrm{~h}$ per month and is provided personally by the residents. From an individual perspective, the rental is cheaper than the use of commercial car sharing services. With regard to a fair financial structure for both lenders and borrowers of mobility services, there may still be room for improvement. In summary, the criterion of financial sustainability can be evaluated as positive. Without project support, however, it is uncertain to what extent and at what cost external expertise would have been available.

Challenges for the viability of the jointly developed concept could arise in dealing with the first cases of damage, the acquisition of new vehicles and public transport tickets, and the potential extension of the service to people outside the close community.

\subsection{Mobility Sharing at Co-Housing in Berlin}

The initial plans to introduce formalised sharing of different means of transport (cars, cargo bikes, public transport tickets) using a booking and billing tool were not implemented. Various changes occurred in the implementation phase that influenced the 
development process and showed that most of the active users had little demand for such a system. After thoroughly analysing the needs and obstacles and conducting several workshops, an informal form of sharing was introduced in the Autumn of 2017. Once the vehicles (and other items) for sharing had been specified, a digitalised list available to all residents was created on the intranet. This list shows which cars, cargo bikes, and public transport tickets are available for sharing and under which conditions. At the end of 2017, two cars, two cargo bikes, a trailer, and two public transport tickets were offered for this purpose. In addition, a calculation tool to determine the recommended rates for lending was provided on the intranet. The use of this tool and further advice on insurance were the result of co-creation and co-design processes with external experts. Direct and informal borrowing between neighbours is another popular form of organisation alongside the sharing structures via the intranet. It is practised especially within the individual buildings and is much valued for its high degree of flexibility and spontaneity, functioning largely without extensive formalisation and organisational support (e.g., no digital booking or accounting tool).

About half the car owners at the co-housing in Berlin make their car available to the sharing service. The average lending frequency is two to three times per month. This comparatively low personal demand is mainly due to the good infrastructure of the urban residential area with its multiple mobility options. Extensive ownership of private cars, bicycles, and tickets for public transport means that most residents can fulfil their individual mobility needs without using the neighbourhood's shared services. The car sharing option is mostly regarded as a supplement for special occasions and less as a substitute for everyday use of the private car. Since no private cars were abolished during the observation period, the service did not affect the amount of parking space at the premises. As sharing is of somewhat low significance, a very limited impact on traffic and energy consumption could be observed. Thus, neither positive nor negative sustainability impacts can be attributed to the services from an ecological perspective.

The sustainability effects in the social dimension show a slight positive development. Neighbourhood mobility sharing helped increase social interaction between residents. The design of the services is functionally adapted to the needs of the users and meets lenders' high demand for flexibility. In response to this, informally organised sharing has proved most suitable for the residents' needs. In order to fulfil certain standards concerning planning, structuring, and planning security, some more formal forms of sharing (e.g., a list of vehicles on the intranet) were implemented as well. The advantages of informal organisational structures also became evident in terms of time sovereignty. In particular, these structures enable lenders to share their vehicles flexibly and often spontaneously. However, the flexibility and spontaneity on the part of the lender is at the expense of the borrower.

The predominantly informal organisation also becomes evident with regard to economic aspects. Sharing between neighbours is seen less as a business model than as a form of neighbourhood assistance. Financial compensation through user fees is therefore hardly paid and is neither expected nor desired by most residents. Given the currently very low frequency of use, there is no negative assessment by the lenders of the additional operating costs through sharing. The low degree of formalisation also means that systemic sustainability is of little importance as long as the sharing is carried out on a more informal, private level. Accordingly, no financial investments were made in the organisation of the communal sharing concept. The amount of time invested as a personal contribution was also rather low. The neighbourhood mobility services are provided solely using privately owned vehicles. Since user fees are hardly charged, this also means that lenders are responsible for all resulting costs of the vehicles: investment costs, maintenance, and operating costs. The low degree of formalisation can act as an obstacle to the collection of regular, costcovering user fees. From a financial point of view, it is mainly the borrowers who currently benefit from the low or non-existent payment practices. In conclusion, the assessment of economic sustainability effects showed a neutral outcome. 


\section{Shared Services to Establish More Sustainable Everyday Practices-Too Much or Worth the Effort?}

The assessment of the three RWLs revealed many findings that can be linked to the research questions and hypotheses raised. Section 4.1 discusses the sustainability assessment of the residential co-housing services in the RWLs and therefore addresses Q1 and H1. In Section 4.2, the findings from the three case studies will be combined in order to draw fundamental conclusions about requirements for a successful implementation of residential services and to facilitate transferability to other contexts. This addresses research question and hypotheses 2 and 3.

\subsection{Findings of the Integrative Sustainability Assessment}

The findings in the literature that residential co-housing services contribute to sustainable behavioural changes in everyday life such as transport and mobility was confirmed on the basis of the integrative sustainability assessment of the services in the three RWLs. However the results differ between the RWLs and the sustainability criteria.

From an ecological viewpoint, the RWLs showed overall positive effects. In the case of the multi-functional room, the high potential of the commonly used space to reduce individual traffic became obvious. The differing ecological effects of the two mobility sharing approaches revealed the importance that the frequency of use of the respective service plays in this regard. Nevertheless, the neutral ecological effects at the co-housing in Berlin were offset by the positive social impacts.

All the services analysed have strong to very strong sustainability impacts in the social dimension. At the co-housing in Pirmasens, the development process of the multifunctional room has led to positive social effects through the community involvement of the residents. Mobility services are likewise seen as collectively produced and community-strengthening elements. Therefore, it can be concluded, that the collaborative development process of shared services in itself already generates positive social effects. Another positive impact can be seen in the flexibility of design. The functionality of each of the shared services is well adapted to the respective needs of the participating residents. A high demand for flexibility and spontaneity led to mobility sharing among neighbours that is practised on a more informal level (co-housing in Berlin), a demand for a more regulated process resulted in a more formalized booking process (co-housing in Greater Berlin).

The great importance of the social aspects in the development of neighbourly sharing services has limiting implications for the economic viability. At the co-housing in Pirmasens and in Greater Berlin there haven't been positive sustainability effects in the economic dimension yet. This is mainly due to the low level of formalisation: the lack of membership fees in Pirmasens, and the understanding of mobility sharing in Greater Berlin as neighbourhood help instead of as a business model, prevented the establishment of a viable and financially self-sufficient model. Only the formalised mobility sharing at co-housing Greater Berlin has already shown positive effects from an economic perspective. The residents were able to set up and operate a functioning system through intensive personal contributions and free consultation and financial support by the project team. This points to the great financial and personal requirements in establishing economic sustainability.

While the consideration of the individual sustainability criteria revealed negative or neutral impacts, these were offset by positive impacts in other aspects in the overall analysis. This shows that a comprehensive analysis of sustainability impacts should be based on an integrative holistic analysis. In order to fully comprehend the sustainability potentials of bottom-up created co-housing initiatives, their ecological, economic, and social impacts have to be taken into consideration, applying an integrated evaluation framework. These findings confirm hypothesis $\mathrm{H} 1$.

The evaluation of the residential services in the three RWLs also shows how differently residential mobility related services can be designed and adapted. Spatial and personal framework conditions need to be considered as well as the residents' specific needs. Nonetheless, the assessment of the sustainability effects of all RWLs underpins the 
assumption that innovative residential services can promote sustainable living. The analysis reveals a broad variety of processes and implementation options for neighbourly sharing services at housing companies and housing initiatives, whilst at the same time it makes clear that innovative concepts in the residential environment can make a significant contribution to ecological, social, and economic sustainability.

\subsection{Requirements for Successful Implementation and Transferability}

Communal sharing services are a growing trend. This momentum can be used as a window of opportunity for urban and transport planning to achieve sustainability goals more effectively. The multifaceted value of communal sharing services in increasing the sustainability of the housing and transport sector is evident. Communal housing forms such as co-housing take up this potential and generate a wide range of added value: better opportunities for participation, trust, and appreciation among residents, positive ecologically effects and, from an economic perspective, higher housing satisfaction and resident loyalty. The results can be summarised in the general requirements for a successful implementation and transferability to other cases in the housing sector and in other cities:

(1) A setting that allows a sound development and management of community-based sharing services.

(2) Early consideration of key actors, different sharing services, open possibilities in the planning process, well-moderated collaborative processes, and the inclusion of existing knowledge.

(3) Investments for start-up and ongoing operations.

These requirements are explained in the following. Here we show typical obstacles in construction planning, district management, urban planning, and transport planning that impede structural changes and that need to be overcome. The strategies in which these obstacles were tackled differ considerably, due to different actors and context conditions in the three RWLs. However, the findings of the RWLs support the assumptions H2 and $\mathrm{H} 3$, indicating key points which have to be considered when transferring co-operative bottom-up created residential services to other parts of the housing sector and making urban planning practices more supportive for bottom up strategies.

(1) The development and management of these services builds on the commitment of all actors involved, but also on learning processes and flexibility. In the three RWLs investigated, the development of the process from the initial idea to the implementation and operation of communal sharing services was not predictable from the beginning. In particular at the co-housing in Pirmasens, the interests of the residents changed significantly during the development process. A shared vision or target proved to be important. Residents do not consider themselves as individual clients but as members of a common initiative. The co-housing initiatives in Berlin and Greater Berlin also manifested discrepancies with these visions in the process of implementation. Here, the legal planning requirements for parking spaces created path dependencies that had a strong impact on the further development of potential services. The requirements of such regulations on the number and location of car parking spaces and their size should therefore be included in the planning process at an early stage. They are difficult to revise at a later date, thereby establishing fixed conditions for car use and ownership and restricting bike use, e.g., in the form of a lack of space for adequate bike parking. The requirements of shared (mobility) services must be considered early on, at the planning and construction stage.

During the planning and construction phase, there was a certain lack of so-called "blank spots" which would have made it possible to develop shared rooms and communal spaces in a more open manner. Early determination of specific forms of use led to discrepancies in the ideas of the residents-for instance in Pirmasens-which then had to be resolved through extensive consultation processes. The only way to clarify residents ${ }^{\prime}$ interests and find a needs-based solution was to develop a common understanding of the visions for and goals of the services. In this process, clear-cut and pragmatic decisions had 
to be made in order to ensure that decisions could be reached at all. The shared vision served as an orientation and guided the further process of creation.

(2) The evaluation of the RWLs showed the great importance of participatory and professionally moderated planning to design solutions that are attractive, user-oriented, and sustainable in the long term. For the latter, co-operation with users in surrounding neighbourhoods could be a viable strategy that goes beyond the scope of the co-housings' own residents. During the project phase, however, this was only pursued to a limited extent by the three RWLs. Most of the services were limited to the initial residential community. A strong commitment to the collaborative spirit of co-housing initiatives might provide a barrier to making these services accessible to users outside the respective initiative. Residents of the co-housing in Greater Berlin acquired both internal and external practical knowledge, which turned out to be a decisive factor in the success of their neighbourhood mobility services. Employees of housing companies and other experts supported the process. By involving external experts, it was possible to work through complex issues and provide important impulses. However, this could only be transformed into needs-oriented solutions by linking it with the residents' internal practical knowledge. This proved to be a successful approach: the skills and talents of the residents were activated in all three real-life laboratories and integrated into the planning and operation. As a result, it was recognised that more emphasis should be placed on participatory and community development processes at the level of neighbourhood and urban planning, supporting the assumption that participatory processes have the potential to enhance the quality of sustainability services and adapt these services to users' needs (H3). In this way, a wide range of creative potential could be tapped into while ensuring an orientation towards the specific needs of the residents. Additionally, the early consideration of future-use concepts can have positive financial effects, since costly conversion measures can be avoided later. At the same time, greater flexibility in building law and in traffic planning at a local level would be necessary in order to implement innovative planning ideas. Furthermore, the consideration of private sector providers (e.g., car sharing providers) can be an important element in facilitating the implementation process.

(3) In addition, affordability and financial viability pose a fundamental challenge. Ideally, the establishment and operation of community sharing services should be closely linked to the calculation of costs and revenues. However, this is not easy, especially in the case of innovative services. On the one hand, revenues are rarely a priority for the users, with the cost-benefit balance being created more on the basis of solidarity and barter transactions. On the other hand, frequency of use is generally confined to estimation due to the novelty of the services. In the case of very informally organised services, there tends to be few technical means or little willingness to record use. The value of personally contributed items (e.g., fitness equipment, garden tools, and even vehicles) is sometimes underestimated by users. In a viable business calculation, depreciation or provisions for replacement investments should be considered to ensure constant availability of equipment, e.g., when cars break down. Maintaining the voluntary commitment is likewise crucial to the enterprise. When it comes to communal housing support services, issues of insurance and liability risks such as those arising from the communal use of private cars should also be considered where appropriate. Housing companies and housing initiatives should therefore also consult mobility service providers, tax experts, and lawyers before introducing new housing support services.

In summary, a high level of effort and a great many details evidently have to be taken into account depending on the service. This can have a deterrent effect on key actors such as housing companies or municipal planners in cities that want to promote co-housing. The processes required are not yet well practiced and in some cases housing companies do not have the necessary competencies or resources. However, the professional approach of many co-housing initiatives shows that such processes can be established and that both architects and planners accept these tasks. There is increasing experience with participatory processes and the external expertise that needs to be involved. Likewise, 
existing human resources could be developed further, for example by incorporating the social management representatives of housing companies. This would be advantageous for a number of reasons: no new staff would have to be recruited, there is a high degree of flexibility, especially in the uncertain initial phase of such planning processes, and a relationship of trust with the residents usually already exists. At the same time, there is no need to reinvent the wheel in order to be successful. It is rather essential to build on the experience of existing services with experience in the field (initiatives, associations or municipal services, mobility service providers) and to make use of external consulting.

\section{Conclusions}

This paper presented the socio-ecological evaluation of three examples of neighbourhood mobility concepts and collaborative uses of space and land in co-housing initiatives that were developed in a co-design between residents and scientists in an RWL. The evaluation used social-empirical methods and secondary analyses. The results show the high sustainability potential of neighbourhood concepts: they enable residents to meet their mobility and housing needs, to use fewer vehicles through shared use, reduce the number of journeys, and to change their choice of transport mode.

However, developing and promoting shared community services has shown to be very pre-conditional and inhibited by factors such as existing planning law, planning/building processes, and actor constellations. This has to be considered by housing companies and initiatives, but as well as—or even more so-by municipal planning administrations, private planning consultancies, and in planning legislation, if the potentials of such services is to be fully exploited.

For a final conclusion, the authors emphasise that urban and transport planning as well as housing companies are called upon to better integrate these insights in planning and developing practices as to systematically use the potential to change, re-design, and re-constellate practices and patterns that affect mobility related behaviour. Bottomup approaches have the potential to change practices and patterns both for self-organized and institutionally initiated participation processes. In summary, our recommendations for these key actors and their role are as follows:

Housing companies and associations act as developers or redevelopment agencies in urban development and are used to provide housing related services. They are thus key actors in sustainability transformations. By developing, establishing, and operating shared community services, they contribute to sustainability goals and thereby achieve better resident loyalty and satisfaction as well as image enhancement. Housing companies can play an important role in strengthening bottom-up initiatives. They can encourage and support residents to participate in the development and organisation of shared community services in order to create solutions that are more user oriented and better suited to the residents' needs.

Municipalities are actors in land allocation and transportation planning. Their practices should be strongly oriented toward the common good. To ensure that innovative concepts can be implemented in a time-effective framework, land or leases should not be awarded on the basis of the best-price principle but by means of so-called concept awarding, as already practiced by some cities in Germany. This instrument could also be used in larger redevelopments and urban renewal processes. In addition, local regulations, such as parking space regulation (German Stellplatzverordnung), should better promote sustainability aspects and allow for new concepts that target lower car ownership rates and must not act as inhibiting factors for more sustainable concepts.

Furthermore, municipalities play a key role as actors that can drive integrated settlement and transport development: mixed-use, small-scale built-spatial structures are considered a core element of planning that avoids traffic and enhances quality of life [22]. This applies not only to new developments but also to the redevelopment of existing areas. The municipalities and the commissioned planners therefore should acknowledge 
that they have a core task and a core competence to reconfigure housing and mobility practices sustainably.

In addition, municipalities can engage in knowledge transfer to support and promote sustainability transformations and provide targeted advice to redevelopment and construction clients. In this way, concept awarding processes and successful implementation can be well linked. This can be done through funding strategies for investments in shared community services or, as is emerging in some places, through support structures for participatory planning and collaborative forms of living.

Author Contributions: Conceptualization, J.D. and I.S.; methodology, J.D., M.W.; validation, formal analysis, investigation, resources, M.W., J.D., I.S.; writing—original draft preparation, J.-M.J., J.D.; writing-review and editing, J.D., I.S., M.W., J.-M.J.; visualization, J.D., J.-M.J.; supervision, I.S.; project administration, J.D.; funding acquisition, J.D., I.S. All authors have read and agreed to the published version of the manuscript.

Funding: This research was funded by the Federal Ministry of Education and Research (BMBF) on the thematic priority "Sustainable management", funding code 01UT1224A-C.

Institutional Review Board Statement: The study was conducted according to the guidelines of the Declaration of Helsinki. The ethical review and approval was done in the project WohnMobil in 2016 and 2018 by a board comparable to an Ethics Committee.

Informed Consent Statement: Informed consent was obtained from all subjects involved in the study.

Data Availability Statement: The main data sources were data collected during the research project at actors and residents of the co-housing initiatives. Restrictions apply to the availability of these data due to anonymity reasons. The data presented in this study are available on request from the corresponding author.

Acknowledgments: We wish to thank all involved residents of the research project WohnMobil. Without their "new living" we wouldn't have been able to investigate the transformation processes. We thank all research and practice partners in this exiting project and our funding agency BMBF and DLR for making the project possible. In addition we wish to thank Maxine Demharter for editing our English and eliminating our mistakes.

Conflicts of Interest: The authors declare no conflict of interest. The funders had no role in the design of the study; in the collection, analyses, or interpretation of data; in the writing of the manuscript, or in the decision to publish the results.

\section{References}

1. Czischke, D. Collaborative housing and housing providers: Towards an analytical framework of multi-stakeholder collaboration in housing co-production. Int. J. Hous. Policy 2018, 18, 55-81. [CrossRef]

2. Scheller, D. Hamburg: Housing movements and local government. In Contemporary Co-Housing in Europe: Towards Sustainable Cities? Hagbert, P., Larsen, H.G., Thörn, H., Wasshede, C., Eds.; Routledge: New York, NY, USA, 2020; pp. 57-73.

3. Shaheen, S.; Cohen, A.; Chan, N.; Bansal, A. Sharing strategies: Carsharing, shared micromobility (bikesharing and scooter sharing), transportation network companies, microtransit, and other innovative mobility modes. In Transportation, Land Use, and Environmental Planning; Deakin, E., Ed.; Elsevier: Amsterdam, The Netherlands, 2020; pp. 237-262.

4. Boyko, C.; Clune, S.; Cooper, R.; Coulton, C.; Dunn, N.; Pollastri, S.; Leach, J.; Bouch, C.; Cavada, M.; de Laurentiis, V.; et al. How Sharing Can Contribute to More Sustainable Cities. Sustainability 2017, 9, 701. [CrossRef]

5. Jonuschat, H.; Scharp, M. Sustainable Home Services in Germany: An Overview on Preconditions, Frameworks and Offers; Werkstattbericht (72); IZT_-Institut für Zukunftsstudien und Technologiebewertung: Berlin, Germany, 2005.

6. Hohm, D.; Jonuschat, H.; Scharp, M.; Scheer, D.; Scholl, G. Innovative Dienstleistungen, Rund um das Wohnen' Professionell Entwickeln. Service Engineering in der Wohnungswirtschaft. Leitfaden; GdW Bundesverband deutscher Wohnungsunternehmen e.V.: Berlin, Germany, 2004.

7. Daly, M. Quantifying the environmental impact of ecovillages and co-housing communities: A systematic literature review. Local Environ. 2017, 22, 1358-1377. [CrossRef]

8. Hacke, U.; Müller, K.; Dütschke, E. Cohousing - social impacts and major implementation challenges. GAIA—Ecol. Perspect. Sci. Soc. 2019, 28, 233-239. [CrossRef]

9. Schäfer, M.; Hielscher, S.; Haas, W.; Hausknost, D.; Leitner, M.; Kunze, I.; Mandl, S. Facilitating Low-Carbon Living? A Comparison of Intervention Measures in Different Community-Based Initiatives. Sustainability 2018, 10, 1047. [CrossRef] 
10. Hagbert, P. Co-housing as a socio-ecologically sustainable alternative? In Contemporary Co-Housing in Europe: Towards Sustainable Cities? Hagbert, P., Larsen, H.G., Thörn, H., Wasshede, C., Eds.; Routledge: New York, NY, USA, 2020; pp. 183-201.

11. Anke, J.; Francke, A.; Schaefer, L.-M.; Petzoldt, T. Impact of SARS-CoV-2 on the mobility behaviour in Germany. Eur. Transp. Res. Rev. 2021, 13, 10. [CrossRef]

12. Warren, M.S.; Skillman, S.W. Mobility Changes in Response to COVID-19. arxiv 2020, arXiv:2003.14228.

13. Bonaccorsi, G.; Pierri, F.; Cinelli, M.; Flori, A.; Galeazzi, A.; Porcelli, F.; Schmidt, A.L.; Valensise, C.M.; Scala, A.; Quattrociocchi, W.; et al. Economic and social consequences of human mobility restrictions under COVID-19. Proc. Natl. Acad. Sci. USA 2020, 117, 15530-15535. [CrossRef] [PubMed]

14. Buheji, M. Sharing Economy and Communities Attitudes after COVID-19 Pandemic-Review of Possible Socio-Economic Opportunities. Am. J. Econ. 2020, 10, 395-406. [CrossRef]

15. Marckmann, B.; Gram-Hanssen, K.; Christensen, T.H. Sustainable Living and Co-Housing: Evidence from a Case Study of Eco-Villages. Built Environ. 2012, 38, 413-429. [CrossRef]

16. Williams, J. Sun, surf and sustainable housing-Cohousing, the Californian experience. Int. Plan. Stud. 2005, 10, 145-177. [CrossRef]

17. Moos, M.; Whitfield, J.; Johnson, L.C.; Andrey, J. Does Design Matter? The Ecological Footprint as a Planning Tool at the Local Level. J. Urban Des. 2006, 11, 195-224. [CrossRef]

18. Haraldsson, H.V.; Ranhagen, U.; Sverdrup, H. Is Eco-living more Sustainable than Conventional Living? Comparing Sustainability Performances between Two Townships in Southern Sweden. J. Environ. Plan. Manag. 2001, 44, 663-679. [CrossRef]

19. Pissourios, I.A. Top-down and Bottom-up Urban and Regional Planning: Towards a Framework for the Use of Planning Standards. Eur. Spat. Res. Policy 2014, 21, 83-99. [CrossRef]

20. Healey, P. Collaborative Planning. Shaping Places in Fragmented Societies; Macmillan Education: London, UK, 1997.

21. Tummers, L. Understanding co-housing from a planning perspective: Why and how? Urban Res. Pract. 2015, 8, 64-78. [CrossRef]

22. Moreno, C. The 15 Minutes-City: For a New Chrono-Urbanism! Available online: http:/ /www.moreno-web.net/the-15-minutescity-for-a-new-chrono-urbanism-pr-carlos-moreno/ (accessed on 14 December 2020).

23. Schneidewind, U.; Scheck, H. Die Stadt als "Reallabor" für Systeminnovationen. In Soziale Innovation und Nachhaltigkeit: Perspektiven Sozialen Wandels; Rückert-John, J., Ed.; Springer VS: Wiesbaden, Germany, 2013; pp. 229-248.

24. Deffner, J. Wohnbegleitende Dienstleistungen in Gemeinschaftlichen Wohnformen: Systematisierung, Fallbeispiele und erste Überlegungen zur Verallgemeinerung. Werkstattbericht. 2017. Available online: http:/ /www.wohnmobil-projekt.de/fileadmin/ user_upload/Geschaeftsmodelle_Werkstattbericht_Rubik_Hummel.pdf (accessed on 14 December 2020).

25. Rubik, F.; Hummel, T. Überblick über Geschäftsmodelle und Anwendung auf Wohnungsunternehmen und Wohninitiativen. Werkstattbericht. 2016. Available online: http://www.wohnmobil-projekt.de/fileadmin/user_upload/Downloads/WohnMobil_ Broschuere.pdf (accessed on 14 December 2020).

26. Schönau, M.; Kasten, P.; Birzle-Harder, B.; Kurzrock, B.-M.; Rubik, F.; Deffner, J. Nachhaltigkeitswirkungen Wohnbegleitender Dienstleistungen in Gemeinschaftlichen Wohnformen. Analyse von Drei Praxisbeispielen Gemeinschaftlicher Flächennutzung und Mobilitätsangebote. Werkstattbericht. 2018. Available online: http://www.wohnmobil-projekt.de/fileadmin/user_upload/ Downloads/Nachhaltigkeitswirkungen_Werkstattbericht.pdf (accessed on 14 December 2020).

27. Deffner, J.; Kasten, P.; Rubik, F.; Schönau, M.; Stieß, I. Wohnbegleitende Dienstleistungen. Nachhaltiges Wohnen durch Innovative Gemeinschaftliche Angebote Fördern. 2018. Available online: http://www.wohnmobil-projekt.de/fileadmin/user_upload/ Downloads/WohnMobil_Broschuere.pdf (accessed on 14 December 2020).

28. Selke, S. Gesellschaft als Labor. Available online: http://blog.soziologie.de/2013/11/gesellschaft-als-labor/\#more-3061 (accessed on 4 February 2021).

29. Jahn, T.; Keil, F. Reallabore im Kontext transdisziplinärer Forschung. GAIA-Ecol. Perspect. Sci. Soc. 2016, 25, 247-252. [CrossRef]

30. Schäpke, N.; Stelzer, F.; Bergmann, M.; Singer-Brodowski, M.; Wanner, M.; Caniglia, G.; Lang, D.J. Reallabore im Kontext Transformativer Forschung: Ansatzpunkte zur Konzeption und Einbettung in den Internationalen Foschungsstand; IETSR Discussion papers in Transdisciplinary Sustainability Research; Leuphana University of Lüneburg: Lüneburg, Germany, 2017.

31. Ukowitz, M. Transdisziplinäre Forschung in Reallaboren: Ein Plädoyer für Einheit in der Vielfalt. GAIA-Ecol. Perspect. Sci. Soc. 2017, 26, 9-12. [CrossRef]

32. Schneidewind, U.; Singer-Brodowski, M. Transformative Wissenschaft. Klimawandel im Deutschen Wissenschafts- und Hochschulsystem, 2nd ed.; Metropolis Verlag: Marburg, Germany, 2014.

33. Beecroft, R.; Parodi, O. Reallabore als Orte der Nachhaltigkeitsforschung und Transformation. Einführung in den Schwerpunkt. Technikfolgenabschätzung-Theorie und Praxis 2016, 25, 4-8. [CrossRef]

34. Reyes Nieto, J.E.; Rigueiro, C.; Da Simões Silva, L.; Murtinho, V. Urban Integrated Sustainable Assessment Methodology for Existing Neighborhoods (UISA fEN), a New Approach for Promoting Sustainable Development. Sustain. Dev. 2018, $26,564-587$. [CrossRef] 